\title{
Suppression of Gluconeogenesis and Endogenous Glucose Production by Exogenous Insulin Administration in the Newborn Lamb
}

\author{
JOHN B. SUSA, ${ }^{(29)}$ RICHARD M. COWETT, WILLIAM OH, AND ROBERT SCHWARTZ
}

Departments of Pediatrics, Rhode Island Hospital and Women and Infants Hospital of Rhode Island, Section on Reproductive and Developmental Medicine, Brown University Program in Medicine, Providence, Rhode Island, USA

\begin{abstract}
Summary
Persistent endogenous hepatic glucose production is characteristic of the newborn lamb in response to exogenous glucose infusion. The hypothesis that decreased hepatic sensitivity for insulin may be a major mechanism accounting for the imprecision in glucose homeostasis was tested in 28 unanesthetized, mixed breed, term lambs. Either 0, 5.7, 6.2, or $12.5 \mathrm{mg}$ glucose $/ \mathrm{kg} / \mathrm{min}$ was infused for a period of $2 \mathrm{hr}$ after which simultaneous infusion of $0,1.25$, or $6.25 \mathrm{mU}$ porcine insulin $/ \mathrm{kg} / \mathrm{min}$ was administered for $\mathbf{4} \mathrm{hr}$ to produce a euglycemic, hyperinsulinemic steady state. Gluconeogenesis from lactate was measured by determining the ratio of ${ }^{14} \mathrm{C}$ to ${ }^{3} \mathrm{H}$ in plasma glucose during the simultaneous infusion of ${ }^{14} \mathrm{C}_{U}$-lactate and ${ }^{3} \mathbf{H}_{6}$-glucose. Endogenous hepatic glucose production was determined by the prime-constant infusion technique of Steele using ${ }^{3} \mathrm{H}_{6}$ radio-labeled glucose during a 50 min turnover period after the infusions. All animals maintained a constant plasma glucose concentration and glucose specific activity during the turnover period. Gluconeogenesis was significantly suppressed when insulin levels were in the $49-61 \mu \mathrm{U} / \mathrm{ml}$ range although endogenous glucose production was not affected. When plasma insulin concentrations were above $200 \mu \mathrm{U} / \mathrm{ml}$, both gluconeogenesis and endogenous glucose production were significantly suppressed. These changes were observed irrespective of the steady state blood glucose concentration. Plasma glucagon concentrations were the same in all experimental groups and were not affected by glucose and insulin infusion nor were they responsive to differences in plasma glucose or insulin concentrations. Our data indicates that insulin may be the major hormone for the control of glucose homeostasis in the neonatal lamb and that there is a quantitative difference in the response of the various glucose homeostatic mechanisms to insulin.
\end{abstract}

\section{Speculation}

Regardless of the plasma glucose concentration and the resultant counter-regulatory responses that may occur during prolonged continuous glucose infusion, endogenous glucose production in the neonatal lamb may be primarily controlled by insulin.

Precise hepatic control of glucose homeostasis in the adult results in the diminution of endogenous glucose production in response to glucose infusion at a rate equal to the basal endogenous glucose production $(5,9,25)$. It is assumed that with glucose infusion, an elevation in plasma glucose and insulin will result in an appropriate reduction of endogenous glucose production and will achieve a new steady state concentration of plasma glucose by insulin which inhibits gluconeogenesis and glycogenolysis and stimulates glycogenesis $(4,6,17)$. In adults, after hepatic glycogen stores are depleted, gluconeogenesis is the most important regulatory mechanism for glucose homeostasis (18). An effective re- duction in gluconeogenesis would result in a reduction in endogenous glucose production.

We have recently shown that the newborn lamb requires a far greater increase in plasma insulin concentration to significantly reduce endogenous glucose production ( 10 -fold increase in plasma insulin vs. 3-fold increase required in adult) (5). The reason for this developmental difference in glucose control is not clear, although we postulated hepatic insensitivity to insulin in the newborn may account for it. In those studies, we produced hyperinsulinemia with hyperglycemia by exogenous glucose infusion; we were unable to differentiate the effect of hyperglycemia from hyperinsulinemia. Furthermore, we did not study gluconeogenesis which is an important regulatory mechanism for glucose homeostasis.

To dissociate the effects of plasma glucose from plasma insulin in the control of glucose production and gluconeogenesis, varying concentrations of glucose and insulin were infused into newborn lambs for sufficient time to produce steady state equilibrium concentrations of plasma glucose and insulin. Plasma glucose, insulin, glucagon, and glucose specific activity were determined and gluconeogenesis and endogenous glucose production were derived.

\section{MATERIALS AND METHODS}

Twenty-eight mixed breed newborn lambs $(3.5 \pm 0.3$ days old; weight $4.6 \pm 0.2 \mathrm{~kg})(\mathrm{M} \pm \mathrm{SE})$ were the subjects of this study. The newborn lambs were allowed to deliver spontaneously and were fed ad libitum by their mother until the study was initiated.

Thereafter, the protocol of fasting, catheterization, stabilization, and initial base line blood sampling has previously been described (5). During the 6-hr infusion period, the animals received either $0.45 \%$ saline or varying concentrations of exogenously administered glucose $(5.7,6.2,12.5$, or $21.7 \mathrm{mg} / \mathrm{kg} / \mathrm{min})$ and 17 animals additionally received exogenous porcine insulin $(1.25$ or $6.25 \mathrm{mU} /$ $\mathrm{kg} / \mathrm{min}$ ) with a separate pump via the external jugular catheter at the $2 \mathrm{nd} \mathrm{hr}$ of the glucose infusion continuously through the experimental period. There was a total of six groups of animals which received various rates of glucose and/or insulin infusion. All groups were of comparable age and weight. Blood sampling for glucose, insulin, and glucagon was done as previously described (5). ${ }^{3} \mathrm{H}_{6}$-D-glucose $(25 \mu \mathrm{Ci} / \mathrm{kg})$, the most suitable and accepted tracer for determining glucose kinetics (7), and ${ }^{14} \mathrm{C}_{\mathrm{U}}-\mathrm{L}$ lactate $(10 \mu \mathrm{Ci} / \mathrm{kg})$ were given simultaneously by the prime-constant infusion technique of Steele et al. (24) after $6 \mathrm{hr}$ of infusion to determine gluconeogenesis and endogenous glucose production.

Six blood samples were obtained during the turnover period for glucose ${ }^{3} \mathrm{H}$ and ${ }^{14} \mathrm{C}$ specific activity. Deproteinized plasma samples were passed through Dowex-1 $\left(\mathrm{Cl}^{-}\right)$and Dowex-50 $\left(\mathrm{H}^{+}\right)$resin columns to separate glucose from lactate and charged glucose metabolites (5). These columns were capable of removing $99.7 \pm$ $0.2 \%$ of lactate and $99.3 \pm 0.3 \%$ of pyruvate added to plasma while 
permitting $99.6 \pm 0.3 \%$ of glucose to pass through. The effluent was collected, lyophilized, and ${ }^{3} \mathrm{H}$ and ${ }^{14} \mathrm{C}$ counts measured. The mean ${ }^{3} \mathrm{H}$ and ${ }^{14} \mathrm{C}$ glucose specific activity was determined (usually within a $\pm 5 \%$ range). Endogenous glucose production was calculated as described by Steele et al. (24). The ratio $(r)$ of the ${ }^{14} \mathrm{C}$ to ${ }^{3} \mathrm{H}$ plasma glucose specific activities, normalized to an equivalent dose of ${ }^{14} \mathrm{C}$-lactate and ${ }^{3} \mathrm{H}$-glucose, was used to measure changes in lactate gluconeogenesis. The $r$ is, however, not a quantitative measure of gluconeogenesis (i.e., percent incorporation) but is a relative measure of changes in the flow of ${ }^{14} \mathrm{C}$ from lactate into glucose.

Plasma glucose, insulin, and glucagon concentrations were determined as previously described (5). Statistical analysis was by paired (for intraanimal comparisons) or unpaired (for interanimal and intergroup comparisons) $t$ tests.

\section{RESULTS}

Figure 1 shows that the base line plasma glucose values were similar in all study groups. The control group (receiving $0.45 \%$ $\mathrm{NaCl}$ ) had a plasma glucose concentration averaging $117 \pm 5$ $\mathrm{mg} / \mathrm{dl}(\mathrm{M} \pm \mathrm{SE})$ during the base line period which stabilized at a mean level of $92 \pm 11 \mathrm{mg} / \mathrm{dl}$ during the turnover period. Lambs receiving 5.6 and $6.2 \mathrm{mg}$ glucose $/ \mathrm{kg} / \mathrm{min}$ evidenced a significant rise in plasma glucose concentration during the infusion period $(P<0.025)$. When $1.25 \mathrm{mU} / \mathrm{kg} / \mathrm{min}$ of exogenous insulin was infused in the animals receiving $6.2 \mathrm{mg}$ glucose $/ \mathrm{kg} / \mathrm{min}$ for $2 \mathrm{hr}$, plasma glucose concentration fell and was similar to that noted in the control animals during the turnover period. The animals receiving $6.2 \mathrm{mg}$ glucose $/ \mathrm{kg} / \mathrm{min}$ and $6.25 \mu \mathrm{U}$ insulin $/ \mathrm{kg} / \mathrm{min}$ were hypoglycemic as evidenced by a plasma glucose concentration $(29 \pm 3 \mathrm{mg} / \mathrm{dl})$ significantly lower than the control animals during the turnover period $(P<0.001)$. The animals receiving $21.7 \mathrm{mg}$ glucose $/ \mathrm{kg} / \mathrm{min}$ had a significant rise in plasma glucose concentration with a mean concentration of $464 \pm 23 \mathrm{mg} / \mathrm{dl}$ during the turnover period.

Animals receiving $12.5 \mathrm{mg}$ glucose $/ \mathrm{kg} / \mathrm{min}$ evidenced a significant rise in plasma glucose concentration after $30 \mathrm{~min}$ of infusion in comparison to the control animals $(P<0.01)$ and in comparison to those groups of animals receiving $6.2 \mathrm{mg}$ glucose $/ \mathrm{kg} / \mathrm{min}(P$ $<0.025$ ). When $6.25 \mathrm{mU}$.of insulin $/ \mathrm{kg} / \mathrm{min}$ was given at $2 \mathrm{hr}$ of infusion, plasma glucose concentration fell to euglycemic levels and plateaued at a mean of $113 \mathrm{mg} / \mathrm{dl}$ during the turnover period. The latter value was similar to those noted in the control animals and in those animals receiving $6.2 \mathrm{mg}$ glucose $/ \mathrm{kg} / \mathrm{min}$ and 1.25 $\mathrm{mU}$ insulin $/ \mathrm{kg} / \mathrm{min}$.
Figure 2 shows the peripheral plasma insulin values of the newborn lambs. The initial base line plasma insulin values averaged $20 \pm 1.8 \mu \mathrm{U} / \mathrm{ml}$ for all lambs and remained stable at $23 \pm 2$ $\mu \mathrm{U} / \mathrm{ml}$ when $0.45 \%$ saline was infused during the turnover period. In those animals receiving 5.7 and $6.2 \mathrm{mg}$ glucose $/ \mathrm{kg} / \mathrm{min}$, there was no statistically significant elevation in plasma insulin concentration during the first $2 \mathrm{hr}$ when compared with the controls. When $1.25 \mathrm{mU}$ insulin $/ \mathrm{kg} / \mathrm{min}$ was infused in those animals receiving $6.2 \mathrm{mg}$ glucose $/ \mathrm{kg} / \mathrm{min}$, a significant elevation of plasma insulin concentration was noted in comparison to the control animals $(P<0.005)$. During the turnover period, the plasma insulin concentration averaged $61 \pm 5 \mu \mathrm{U} / \mathrm{ml}$ in these animals. The animals receiving $21.7 \mathrm{mg}$ glucose $/ \mathrm{kg} / \mathrm{min}$ had plasma insulin concentrations of $316 \pm 138 \mu \mathrm{U} / \mathrm{ml}$ during the turnover period. In the group receiving $6.2 \mathrm{mg}$ glucose $/ \mathrm{kg} / \mathrm{min}$ and $6.25 \mathrm{mU}$ insulin/ $\mathrm{kg} / \mathrm{min}$, the plasma insulin concentration reached an average of $236 \pm 15 \mu \mathrm{U} / \mathrm{ml}$, significantly different from the control animals $(P<0.001)$ and significantly different in comparison to those animals who received $6.2 \mathrm{mg}$ glucose $/ \mathrm{kg} / \mathrm{min}$ and $1.25 \mathrm{mU}$ insu$\mathrm{lin} / \mathrm{kg} / \mathrm{min}(P<0.05)$.

The animals receiving $12.5 \mathrm{mg}$ glucose $/ \mathrm{kg} / \mathrm{min}$ had a significantly higher plasma insulin concentration during the first $2 \mathrm{hr}$ of the infusion period in contrast to the control animals $(P<0.05)$, and in contrast to the animals receiving $6.2 \mathrm{mg}$ glucose $/ \mathrm{kg} / \mathrm{min}$ $(P<0.05)$. These differences were accentuated when $6.25 \mathrm{mU}$ insulin $/ \mathrm{kg} / \mathrm{min}$ was administered for the final $4 \mathrm{hr}$ of the infusion period as well as during the turnover period. During the turnover period, the average plasma insulin concentration was $481 \pm 52$ $\mu \mathrm{U} / \mathrm{ml}$, significantly higher than when neither glucose nor insulin was infused to the control animals $(P<0.001)$ or when $6.2 \mathrm{mg}$ glucose $/ \mathrm{kg} / \mathrm{min}$ was infused with either 1.25 or $6.25 \mathrm{mU}$ insulin/ $\mathrm{kg} / \mathrm{min}$, respectively $(P<0.025)$.

Figure 3 shows the plasma glucagon levels for the neonatal lambs. There were no statistical differences between initial basal glucagon levels in any of the groups. While the average plasma glucagon concentration remained elevated throughout the infusion and turnover periods for the control animals, there were no statistical differences between the control group and any group infused with glucose and insulin.

Figure 4 shows that increasing the rate of glucose infusion without insulin administration (groups 2 and 3) produced a stepwise increase in plasma glucose and insulin concentrations when compared with controls (group 1). The hyperglycemia induced elevation in plasma insulin concentration is associated with a significant $(P<0.05$ in group 2 and $P<0.001$ in group 3$)$ reduction in gluconeogenesis, but the significant $(P<0.001)$

\section{PLASMA GLUCOSE $(\mathrm{mg} / \mathrm{dl})$}

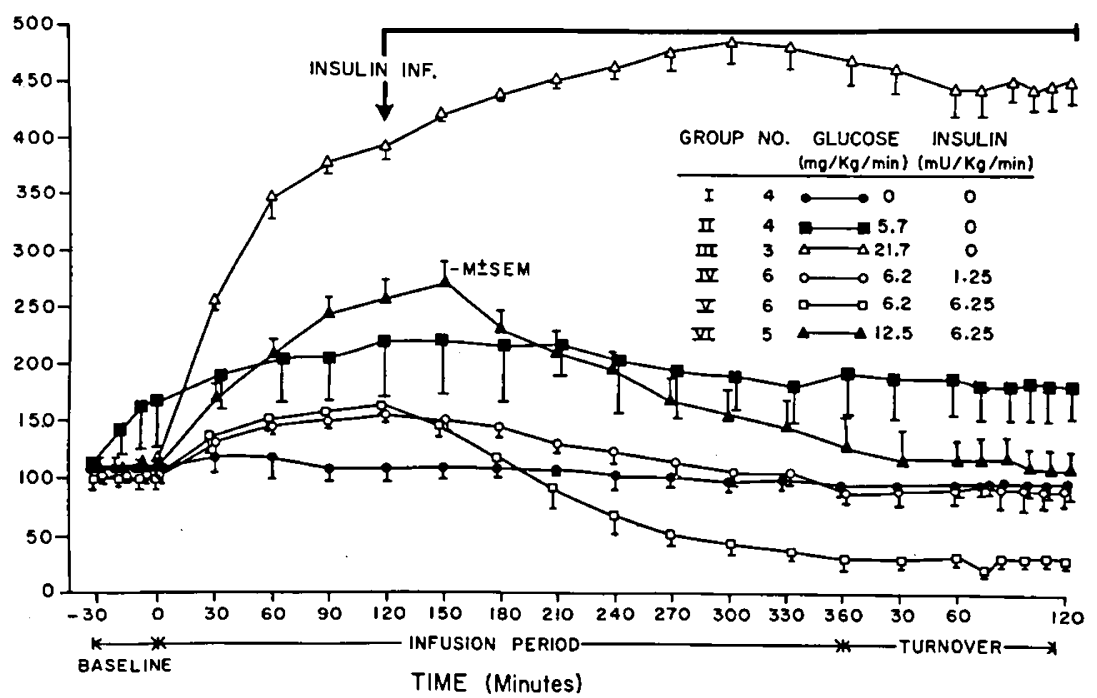

Fig. 1. Plasma glucose values in the newborn lambs after exogenous glucose and insulin infusions at rates indicated. 


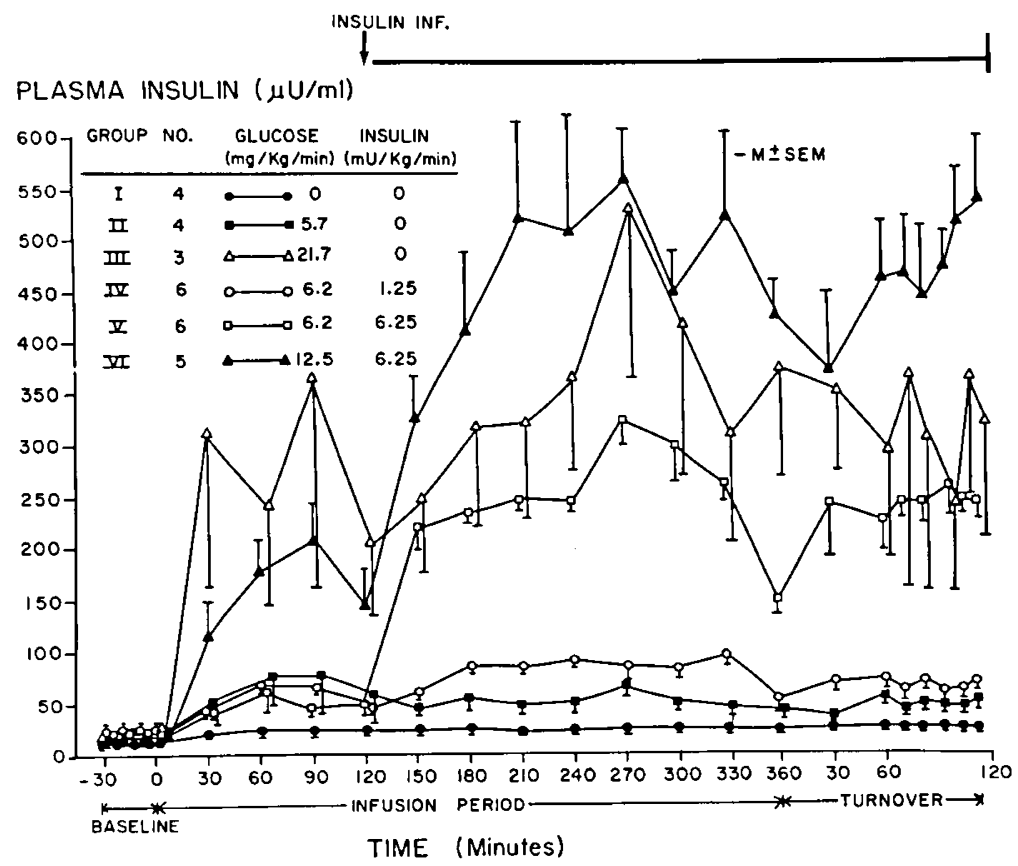

Fig. 2. Plasma insulin values in the newborn lambs after exogenous glucose and insulin infusions at rates indicated.

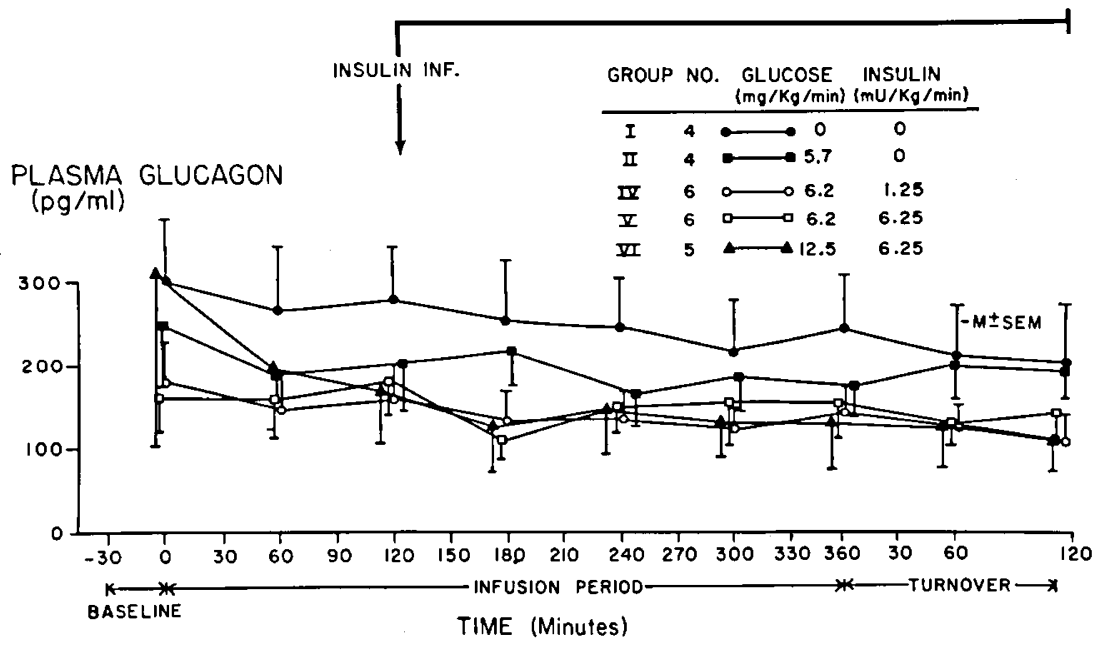

Fig. 3. Plasma glucagon values in the newborn lambs after exogenous glucose and insulin infusions at rates indicated.

reduction in endogenous glucose production is seen only when marked hyperglycemia and hyperinsulinemia were achieved (group 3). With insulin administration, we observed a significant $(P<0.001)$ and stepwise increase in plasma insulin depending on the dose of insulin given and, at the same time, by simultaneous glucose infusion we produced a state of euglycemia or hyperglycemia in association with the hyperinsulinemic state. With a slight increase in plasma insulin $(61 \mu \mathrm{U} / \mathrm{ml}$, group 4$)$, we produced a significant $(P<0.001)$ reduction in gluconeogenesis with a slight, but not significant reduction in endogenous glucose production. With moderate to marked hyperinsulinemia ( 236 and $481 \mu \mathrm{U} / \mathrm{ml}$, groups 5 and 6$)$, there was significant $(P<0.005)$ reduction of gluconeogenesis and endogenous glucose production with hypoglycemia (group 5) and euglycemia (group 6).

\section{DISCUSSION}

Original observations by Soskin et al. (22) suggested the hypothesis of autoregulation of hepatic glucose production by the magnitude of glucose delivery to the liver, which has been confirmed by others $(8,15)$. In fact, Bishop et al. (3) and Steele et al. (23) have suggested that infused glucose decreases endogenous glucose production by causing an increase in the rate of endogenous insulin secretion, which others (13) believe is similar to what occurs physiologically upon ingestion of a high carbohydrate meal.

In adult sheep, we have demonstrated a significant reduction in endogenous glucose production when peripheral plasma insulin was raised to a mean of $50 \mu \mathrm{U} / \mathrm{ml}$ by glucose infusion (5). In lambs, we have also demonstrated that a significantly higher plasma insulin level is required to effectively reduce the endogenous glucose production. We postulated that the reason for this difference in adult and newborn lambs with respect to the insulin effect on endogenous glucose production is due to the hepatic insensitivity to insulin in the neonate. We also raised the question of the role of hyperglycemia and its autoregulatory effect on glucose homeostasis which may influence the endogenous glucose production rate. Therefore, in this study, we manipulated the experimental groups to produce various levels of plasma glucose and insulin concentrations so that different magnitudes of hyperinsulinemia could be achieved with either hypo-, hyper-, or euglycemic states. With these variables, we have examined their effects on gluconeogenesis as well as endogenous glucose production, simultaneously assessed in the same animals. 


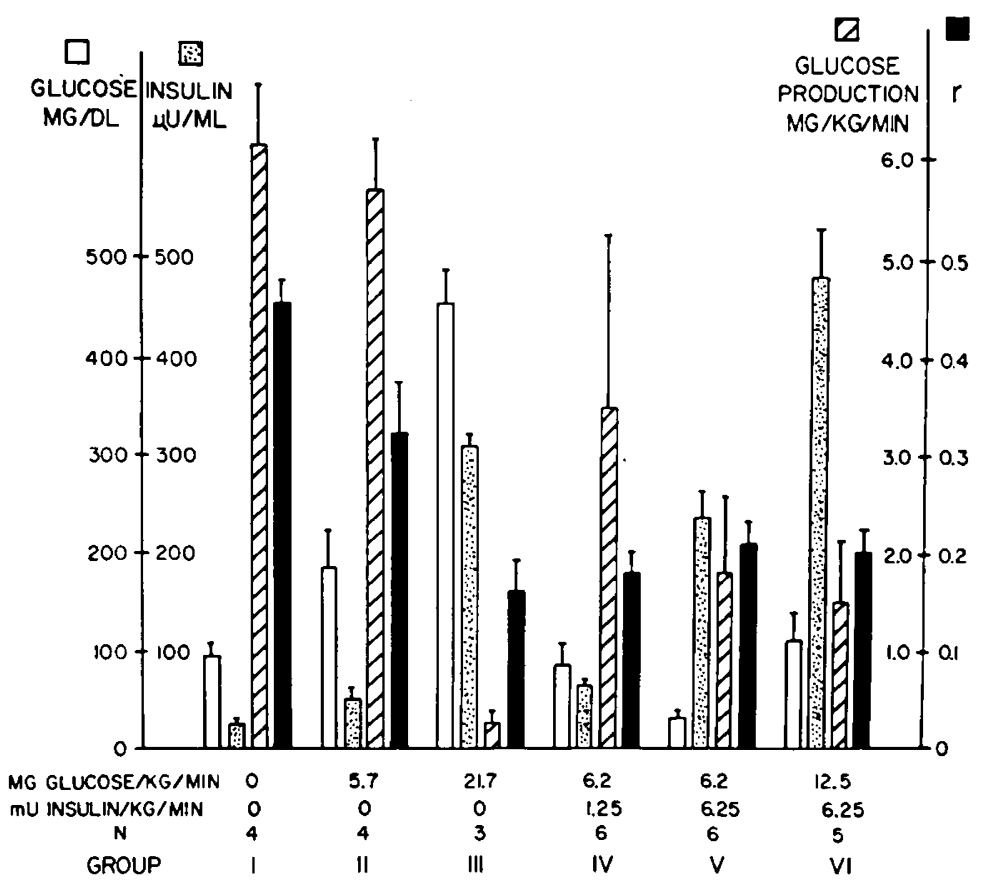

Fig. 4. Plasma glucose and insulin concentrations, endogenous glucose production rate, and ratio of incorporation $(r)(\mathrm{M} \pm \mathrm{SE})$ of ${ }^{14} \mathrm{C}$ from infused lactate found in plasma glucose to the ${ }^{3} \mathrm{H}$ from the infused glucose found in plasma glucose (see Materials and Methods in text) in the newborn lamb after exogenous glucose and insulin infusions. Data are presented from the steady state periods during which glucose turnover was determined.

When subjects are studied in a steady metabolic state, the interpretation of tracer kinetics is simplified compared to when disequilibrium states are analyzed. Our experiments were designed so that a steady state for glucose and insulin was achieved during the determination of gluconeogenesis and endogenous glucose production. We have quantified endogenous glucose production by the method of Steele et al. (24).

The de novo production of ${ }^{14} \mathrm{C}$-labeled glucose by lambs infused with ${ }^{14} \mathrm{C}$-lactate demonstrates that gluconeogenesis from lactate is occuring in the presence of various concentrations of glucose and insulin. Although neither the rate of gluconeogenesis nor the amount of new glucose produced can be measured by the ${ }^{14} \mathrm{C}$ lactate infusion technique as we employed it, the ratio $r$ determined when steady state glucose concentrations and ${ }^{14} \mathrm{C}$ and ${ }^{3} \mathrm{H}$ specific activities exist identifies relative changes of magnitude in lactate gluconeogenesis. A decrease in $r$ indicates a decrease in the amount of ${ }^{14} \mathrm{C}$ incorporation into glucose and, hence, an unquantified decrease in lactate gluconeogenesis.

The systemic administration of insulin in these studies is nonphysiologic and the measurement of peripheral insulin concentration does not allow us to determine the concentration of insulin reaching the liver through the portal system. It has been assumed that peripheral insulin concentration is in synchrony with the insulin concentration in the portal circulation (i.e., parallels peripheral venous levels during infusion of insulin) and that changes in peripheral insulin concentrations are related to changes in hepatic metabolism. Because hepatic extraction of insulin has been demonstrated to be highly variable, only gross changes are interpretable (11).

The rates of endogenous glucose production in the lambs receiving saline or $5.7 \mathrm{mg}$ glucose $/ \mathrm{kg} / \mathrm{min}$ are similar to those reported for the fetal lamb or suckling lamb (26) and the preterm and term Rhesus monkey (21). Infusion of $8 \mathrm{mg}$ glucose $/ \mathrm{kg} / \mathrm{min}$ to preterm Rhesus monkeys causes a decrease in endogenous glucose production in those animals which responded with a significant increase in plasma insulin concentration. The animals which did not have a significant insulin response, however, did not decrease endogenous glucose production. Although there are species and experimental design differences, our data also indicate that insulin plays a key role in the control of endogenous glucose production.
Glycogenesis, glycogenolysis, and gluconeogenesis are the major mechanisms for the control of hepatic glucose production. Insulin inhibits glycogenolysis and gluconeogenesis and enhances glycogenesis resulting in the net suppression of endogenous glucose production $(4,6,17)$. Our data show that a moderate elevation of plasma insulin level effectively reduced gluconeogenesis (groups 2 and 4), but did not influence endogenous glucose production. The latter is reduced only when a much higher insulin level was achieved (groups 3, 5, 6).

These observations may be based on two underlying reasons: 1) gluconeogenesis in the neonate may not be a dominant mechanism for glucose homeostasis, therefore, a reduction in this process may not effectively influence the overall endogenous glucose production rate; 2 ) there may be a quantitative difference in the plasma insulin requirement to influence the enzymatic activities controlling the various hepatic glucose regulatory mechanisms.

The paradoxical persistence of gluconeogenesis even when significant hyperglycemia and hyperinsulinemia are present may, however, be a result of futile cycling. Rognstad et al. $(19,20)$ have demonstrated in both kidney cortex segments and isolated liver parenchymal cells of the rat that gluconeogenesis is isotopically reversible. This is documented by the fact that during active gluconeogenesis, i.e., net glucose synthesis, label from ${ }^{14} \mathrm{C}_{U}$-glucose or ${ }^{14} \mathrm{C}_{1}$-galactose can be found in "glycolytic" products such as lactate, amino acids, and $\mathrm{CO}_{2}$. Friedman et al. (12) have demonstrated pyruvate recycling during gluconeogenesis at a rate nearly one-half of the gluconeogenic rate in perfused rat liver.

It has been suggested that glucose concentration may play an autoregulatory role in glucose homeostasis by various mechanisms including its influence on glucagon, epinephrine, and adrenal cortical hormones $(14,16,23)$. This concept probably does not apply in the neonatal lamb for the following two reasons: 1) the plasma glucagon concentrations were similar in all study groups and 2) the observed changes in gluconeogenesis and endogenous glucose production under the influence of various insulin levels were similar in either hypo-, hyper-, or euglycemic states.

Under conditions of prolonged (6-8 hr) continuous glucose administration, endogenous glucose production in the neonatal lamb appears to be controlled by circulating insulin. Glucagon, a potent glycogenolytic and gluconeogenic stimulator in acute experiments $(1,18)$, appears not to be capable of stimulating gluco- 
neogenesis or glycogenolysis under conditions of insulin-induced hypoglycemia. Review of plasma glucagon concentrations in response to the combination of exogenous glucose and insulin infusions reemphasizes the failure of significant response to either hypo- or hyperglycemia in the neonate that we have noted previously in response to exogenous glucose alone (5) and that has been noted by others in adult sheep (2). Plas and Nunez (18) report that in cultured fetal hepatocytes, a resistance to glucagon stimulation appears after a first stimulation. This phenomenon may be operative in our experiments which would then support the suggestion of Felig et al. (10) that glucose homeostasis is achieved in response to $\beta$-cell pancreatic secretion rather than a combined $\alpha$ and $\beta$-cell response.

\section{REFERENCES AND NOTES}

1. Ayuso-Parrilla, M. S., Martin-Requero, A., and Parrilla, R.: On the mechanism of glucagon stimulation of hepatic gluconeogenesis. Pflügers Arch., 370: 45 (1977).

2. Bassett, J. M.: Plasma glucagon concentration in sheep: their regulation and relation to concentrations of insulin and growth hormone. Aust. J. Biol. Sci., 25: 1277 (1972).

3. Bishop, J. S., Steele, R., Altszuler, N., Dunn, A., Bjerknes, C., and DeBodo, R. C.: Effect of insulin on liver glycogen synthesis and breakdown in the dog. Am. J. Physiol., 208: 307 (1965).

4. Clark, M. G., Filsell, O. H., and Jarrett, I. G.: Gluconeogenesis in isolated intact lamb liver cells. Biochem. J., 156: 671 (1976).

5. Cowett, R. M., Susa, J. B., Oh, W., and Schwartz, R.: Endogenous glucose production during constant glucose infusion in the newborn lamb. Pediatr. Res. 12: 853, 1978.

6. Curnow, R. T., Rayfield, E. J., George, D. T., Zenser, T. V., and DeRubertis, F.: Control of hepatic glycogen metabolism in the rhesus monkey: effect of glucose, insulin and glucagon administration. Am. J. Physiol., 228: 80 (1975).

7. Dunn, A., Katz, J., Golden, S., and Chenowet, M.: Estimation of glucose turnover and recycling in rabbits using various $\left({ }^{3} \mathrm{H},{ }^{14} \mathrm{C}\right)$ glucose labels. Am. J. Physiol., 230: 1159 (1976).

8. Felig, P., and Wahren, J.: Influence of endogenous insulin secretion on splanchnic glucose and amino acid metabolism in man. J. Clin. Invest., 50: 1702 (1971).

9. Felig, P., Wahren, J., Hendler, R., and Brundin, T.: Splanchnic glucose and amino acid metabolism in obesity. J. Clin. Invest., 53: 582 (1974).

10. Felig, P., Wahren, J., Sherwin, R., and Hendler, R.: Insulin, glucagon, and somatostatin in normal physiology and diabetes mellitus. Diabetes, 25: 1091 (1976).

11. Field, J. B.: Extraction of insulin by liver. Ann. Rev. Med., 24: 309 (1973).

12. Friedman, B., Goodman, E. H., Saunders, H. L., Kostos, V., and Weinhouse, S.:
An estimate of pyruvate recycling during gluconeogenesis in the perfused rat liver. Arch. Biochem. Biophys., 143: 566 (1971).

13. Landau, B. R., Leonards, J. R., and Barry, F. M.: Regulation of blood glucose concentrations: Response of liver to glucose administration. Am. J. Physiol., 201: 41 (1961).

14. Leonards, J. R., Landau, B. R., Craig, J. W., Martin, F. I. R., Miller, M., and Barry, F. M.: Regulation of blood glucose concentration: Hepatic action of insulin. Am. J. Physiol., 201: 47 (1961).

15. Long, C. L., Spencer, J. L., Kinney, J. M., and Geiger, J. W.: Carbohydrate metabolism in normal man and effect of glucose infusion. J. Appl. Physiol., 31: 102 (1971).

16. Madison, L. K., Combes, B., Adams, R., and Strickland, W.: The physiological significance of the secretion of endogenous insulin into the portal circulation. III. Evidence for a direct immediate effect of insulin on the balance of glucose across the liver. J. Clin. Invest., 39: 507 (1960).

17. Owen, O. E., Patel, M. S., Block, B. S. B., Kreulen, T. H., Reichle, F. A., and Mozzoli, M. A.: Gluconeogenesis in normal, cirrhotic and diabetic humans, In: R. W. Hanson and M. A. Mehlman: Gluconeogenesis. Its Regulation in Mammalian Species. p. 533 (Wiley Interscience, New York, 1976).

18. Plas, C., and Nunez, J.: Glycogenolytic response to glucagon of cultured fetal hepatocytes. J. Biol. Chem., 250: 5304 (1975).

19. Rognstad, R., Clark, D., and Katz, J.: Relationship between isotopic reversibility and futile cycles in isolated rat liver parenchymal cells. Biochem. Biophys. Res. Commun., 54: 1149 (1973).

20. Rognstad, R., Genovese, J., and Katz, J.: The determination of reversibility in the gluconeogenic pathway. Fed. Proc., 29: 675 (1970).

21. Sherwood, W. G., Hill, D. E., and Chance, G.: Glucose homeostasis in preterm rhesus monkey neonates. Pediatr. Res., 11: 874 (1977).

22. Soskin, S., Alweiss, M. D., and Cohn, D. J.: Influence of the pancreas and liver on dextrose tolerance curve. Am. J. Physiol., 109: 155 (1934).

23. Steele, R., Bishop, J. S., Dunn, A., Altszuler, N., Rathgeb, I., and DeBodo, R. C.: Inhibition by insulin of hepatic glucose production in the normal dog. Am. J. Physiol., 208(2): 301 (1965).

24. Steele, R., Wall, J. E., DeBodo, R. C., and Altszuler, N.: Measurement of size and turnover rate of body glucose pool by the isotopic dilution method. Am. J. Physiol., 187: 15 (1956).

25. Varma, S., Nickerson, H., Cowan, J. S., and Hetenyi, G.: Homeostasis response to glucose loading in newborn and young dogs. Metabolism, 22: 1367 (1973).

26. Warnes, D. M., Seamark, R. F., and Ballard, F. J.: Metabolism of glucose, fructose, and lactate in vivo in chronically cannulated foetuses and in suckling lambs. Biochem. J., 162: 617 (1977).

27. The authors thank Mrs. Kathy Petzold and Mr. William Boto for their technical assistance, and Ms. Donna Perry for secretarial assistance.

28. This research was supported by USPHS Grant HD 8977 and the Rhode Island Hospital Research Fund and USPHS Grant HD 11343.

29. Requests for reprints should be addressed to: John B. Susa, Ph.D., Department of Pediatrics, Rhode Island Hospital, 593 Eddy Street, Providence, RI 02902 (USA).

30. Received for publication January 19, 1978.

31. Accepted for publication May 18, 1978. 